\title{
Prediction and Estimation of Electroplating Characteristics, Corrosion Rate of Zinc Coated Mild Steel Coupling
}

\author{
D.O.I - 10.51201/12505 \\ https://doi.org/10.51201/12505 \\ Dr. S. RAJKUMAR ${ }^{1}{ }^{*}$, LIJALEM M. ${ }^{2}$, AKLILU T. ${ }^{3} \&$ Dr. V. MOHANAVEL \\ 1,2,3 Department of Mechanical Engineering, Faculty of Manufacturing, Institute of \\ Technology, Hawassa University, Hawassa, Ethiopia. \\ ${ }^{4}$ Department of Mechanical Engineering, Bharath Institute of Higher Education and Research, \\ Chennai - 600073, Tamilnadu, India.
}

\begin{abstract}
This present research work is taken to estimate the corrosion rate of zinc coated mild steel coupling with using of Design of Experiments (DOE). Now a day's mild steel materials are simply corroded in the all medium including atmospheric conditions. Overcome of this planed to applying the zinc coating on the mild steel material. In this study considered of normal use of mild steel coupling for the industrial applications. Main goal of this study to evaluate the Coating thickness $(\mu \mathrm{m})$, Change of mass $(\mathrm{g})$ and Corrosion rate $(\mathrm{mm} / \mathrm{y})$ of the coupling after coating. The L16 Orthogonal array of Taguchi analysis is engaged to find the response values. The different process parameters are considered for to analysis of electroplating characteristics, corrosion rate. Process parameters are namely current density (0.3 amps/ dm2,0.5 amps/ dm2,0.7 amps/ dm2 and 0.9 amps/ dm2), concentration of Zinc (10 $\mathrm{g} / \mathrm{L}, 12 \mathrm{~g} / \mathrm{L}, 14 \mathrm{~g} / \mathrm{L}$ and $16 \mathrm{~g} / \mathrm{L})$, coating time $(45 \mathrm{~min}, 60 \mathrm{~min}, 75 \mathrm{~min}$ and $90 \mathrm{~min}$ ) and temperature (20oC, $30 \circ \mathrm{C}, 40 \mathrm{oC}$ and $50 \mathrm{oC}$ ).
\end{abstract}

Key words: Change of mass; Taguchi; Electroplating; Corrosion rate; DOE; Coupling.

\section{INTRODUCTION}

Nowadays the protections of the steel components from corrosion resistance is the big issue to overcome this problem need for some coating process. In recent trends the Zinc electroplating is most powerful method to form a effective coating on the surfaces, Now this method focused to using in steel parts to prevent also protect the surfaces from the corrosion process [1]. Zinc electroplating is the simple process and it has low cost method also best suitable for low budget fabrication process. Compared to other deposition methods Zinc electroplating technology was more powerful, in expenditures wise most of the manufacturing industries preferred this deposition process. This type of deposition process mostly used in automotive industries example to protect the power steering components, brake components bolt and nuts etc. In this process are used in military applications for offered the long life and excellent corrosion resistance of the components [2-4] Normally pure zinc offered moderate levels of corrosion resistance but adding of Nickel more than $10 \%$ highly improve the corrosion resistance [5-7]. Some of the process parameters are influenced the deposition rate such as temperature, current density, zinc concentration, time period and additive application. The thin coating on the surfaces through electroplating protected the surface of the metal that thin coating is also termed as substrate $[8,9]$. 


\section{Experimental Procedure}

This research study considered themild steel coupling for carrying the electroplating process. The Figure 1 illustrates that the before and after electroplating coupling.

a

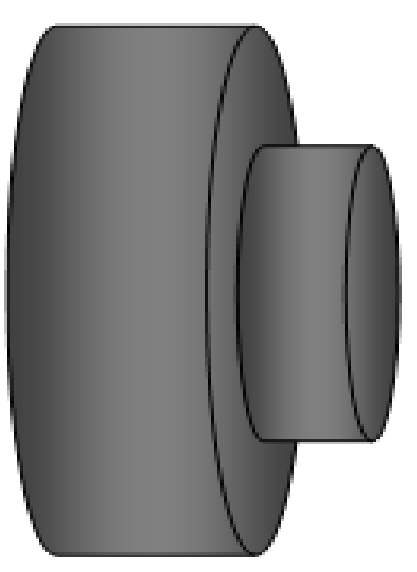

b

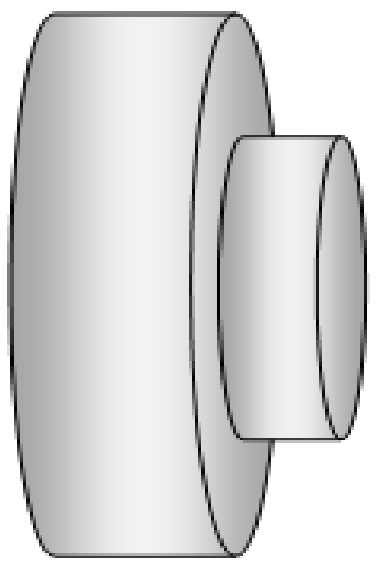

\section{Figure 1. Electroplating Coupling: (a) Before Electroplating (b) After Electroplating}

Before carrying the electroplating process the metal part can be cleaned thoroughly to removing contamination on the surfaces of the mild steel coupling, normally alkaline medium was used to clean the surface. After cleaning the mild steel coupling immersed in the acidic zinc solutions [10-12]. The time period and current density are the key role of the electroplating process. DC supply was provided in the elctroplating process when given the supply the zinc ions from the anode depositing on the cathode (mild steel coupling). During the elctroplating process the uniform current will be supplied it is the response of uniform coating. Finally the zinc electroplated mild steel material was taken out and cleaned by running water after then allowed to dried.For this study mild steel chemical constitutents elements and the percentage of each elements possessesof are presented in the Table 1.

Table 1. Chemical Composition of Mild Steel

\begin{tabular}{|c|c|}
\hline Constituent Elements & Percentage level (\%) \\
\hline Carbon, $\mathrm{C}$ & $0.25-0.290 \%$ \\
\hline Copper, $\mathrm{Cu}$ & $0.20 \%$ \\
\hline Iron, Fe & $98.0 \%$ \\
\hline Manganese, $\mathrm{Mn}$ & $1.03 \%$ \\
\hline Phosphorous, $\mathrm{P}$ & $0.040 \%$ \\
\hline Silicon, $\mathrm{Si}$ & $0.280 \%$ \\
\hline Sulfur, S & $0.050 \%$ \\
\hline
\end{tabular}


Table 2. Mechanical Properties of Mild Steel

\begin{tabular}{|c|c|}
\hline Mechanical Properties & Values \\
\hline Ultimate tensile Strength & $400-550 \mathrm{MPa}$ \\
\hline Yield Strength & $250 \mathrm{MPa}$ \\
\hline Modulus of Elasticity & $200 \mathrm{GPa}$ \\
\hline Bulk Modulus & $140 \mathrm{GPa}$ \\
\hline Poissons Ratio & 0.260 \\
\hline Shear Modulus & $79.3 \mathrm{GPa}$ \\
\hline
\end{tabular}

The Table 2. presented the mechanical properties of mild steel, the mild steel possesses highest ultimate tensile strength and the yield strength offered as $250 \mathrm{MPa}$. All the mechanical properties are good compared to other materials. Mild steel has normally better ductility nature as well as superior strength and also low cast material. It has used in all types of industries laborateries, fabrication process units, in construction work due to long life. Table 3 presented that the Input Process parameters of electroplating process and their levels. In this test taken as a four process parameters such as current density (amps/ $\mathrm{dm}^{2}$ ), concentration of Zinc $(\mathrm{g} / \mathrm{L})$, coating time $(\mathrm{min})$ and temperature $\left({ }^{\circ} \mathrm{C}\right)$. All the parameters are considered four levels of input readings to used in the statistical analysis.

Table 3 Input Process Parameters of Electroplating Process and their Levels

\begin{tabular}{|c|c|c|c|c|}
\hline Process Parameters & Level - 1 & Level - 2 & Level - 3 & Level - 4 \\
\hline $\begin{array}{c}\text { Current Density } \\
\left(\text { amps/ dm }{ }^{2}\right)\end{array}$ & 0.3 & 0.5 & 0.7 & 0.9 \\
\hline $\begin{array}{c}\text { Concentration of Zinc } \\
(\mathbf{g} / \mathbf{L})\end{array}$ & 10 & 12 & 14 & 16 \\
\hline $\begin{array}{c}\text { Coating Time (min) } \\
\text { Temperature }\left(^{\mathbf{0}} \mathbf{C}\right)\end{array}$ & 45 & 60 & 75 & 90 \\
\hline
\end{tabular}




\section{Results and Discussion}

\begin{tabular}{|c|c|c|c|c|c|c|c|}
\hline $\begin{array}{c}\text { Trial } \\
\text { No. }\end{array}$ & $\begin{array}{c}\text { Current } \\
\text { Density } \\
(\text { amps/ } \\
\left.\mathbf{d m}^{2}\right)\end{array}$ & $\begin{array}{c}\text { Concentration } \\
\text { of Zinc } \\
(\mathrm{g} / \mathrm{L})\end{array}$ & $\begin{array}{c}\text { Coating } \\
\text { Time } \\
\text { (min) }\end{array}$ & $\begin{array}{c}\text { Temperature } \\
\left({ }^{\circ} \mathrm{C}\right)\end{array}$ & $\begin{array}{c}\text { Coating } \\
\text { Thickness } \\
(\mu \mathrm{m})\end{array}$ & $\begin{array}{c}\text { Change } \\
\text { of Mass } \\
\text { (g) }\end{array}$ & $\begin{array}{c}\text { Corrosion } \\
\text { Rate } \\
(\mathbf{m m} / \mathbf{y})\end{array}$ \\
\hline 1 & 0.3 & 10 & 45 & 20 & 0.91 & 25.78 & 0.0350 \\
\hline 2 & 0.3 & 12 & 60 & 30 & 1.24 & 32.64 & 0.0680 \\
\hline 3 & 0.3 & 14 & 75 & 40 & 0.97 & 40.29 & 0.0470 \\
\hline 4 & 0.3 & 16 & 90 & 50 & 1.45 & 33.27 & 0.2800 \\
\hline 5 & 0.5 & 10 & 60 & 40 & 1.37 & 29.65 & 0.0430 \\
\hline 6 & 0.5 & 12 & 45 & 50 & 1.26 & 31.48 & 0.0940 \\
\hline 7 & 0.5 & 14 & 90 & 20 & 0.86 & 30.89 & 0.0089 \\
\hline 8 & 0.5 & 16 & 75 & 30 & 1.02 & 39.24 & 0.0750 \\
\hline 9 & 0.7 & 10 & 75 & 50 & 1.56 & 29.98 & 0.1030 \\
\hline 10 & 0.7 & 12 & 90 & 40 & 1.42 & 41.23 & 0.0280 \\
\hline 11 & 0.7 & 14 & 45 & 30 & 1.51 & 37.85 & 0.0610 \\
\hline 12 & 0.7 & 16 & 60 & 20 & 0.99 & 28.67 & 0.0097 \\
\hline 13 & 0.9 & 10 & 90 & 30 & 0.82 & 41.26 & 0.0190 \\
\hline 14 & 0.9 & 12 & 75 & 20 & 1.38 & 35.37 & 0.0420 \\
\hline 15 & 0.9 & 14 & 60 & 50 & 1.64 & 36.81 & 0.0640 \\
\hline 16 & 0.9 & 16 & 45 & 40 & 1.19 & 34.69 & 0.0346 \\
\hline
\end{tabular}

Table 4. Output summary of Electroplating process

The Table 4 presented the entire output summary of the electroplating process. There are three response values are to be considered for this experiment as Coating thickness $(\mu \mathrm{m})$, Change of mass $(\mathrm{g})$ and Corrosion rate $(\mathrm{mm} / \mathrm{y})$. The maximum coating thickness $1.64 \mathrm{~mm}$ was obtained by using of $0.9 \mathrm{amps} / \mathrm{dm}^{2}$ of current density, $14 \mathrm{~g} / \mathrm{L}$ of concentration of Zinc, 60 min of coating time and $50{ }^{\circ} \mathrm{C}$ of temperature. Next the maximum change of mass $41.26 \mathrm{~g}$ was obtained by the influence of $0.9 \mathrm{amps} / \mathrm{dm}^{2}$ of current density, $10 \mathrm{~g} / \mathrm{L}$ concentration of Zinc, 90 min of coating time and $30{ }^{\circ} \mathrm{C}$ temperature. Minimum corrosion rate was recorded as $0.0097 \mathrm{~mm} / \mathrm{yr}$ and the parameters influenced were $0.7 \mathrm{amps} / \mathrm{dm}^{2}$ of current density, $16 \mathrm{~g} / \mathrm{L}$ of concentration of Zinc, $60 \mathrm{~min}$ of coating time and $20{ }^{\circ} \mathrm{C}$ of temperature. 


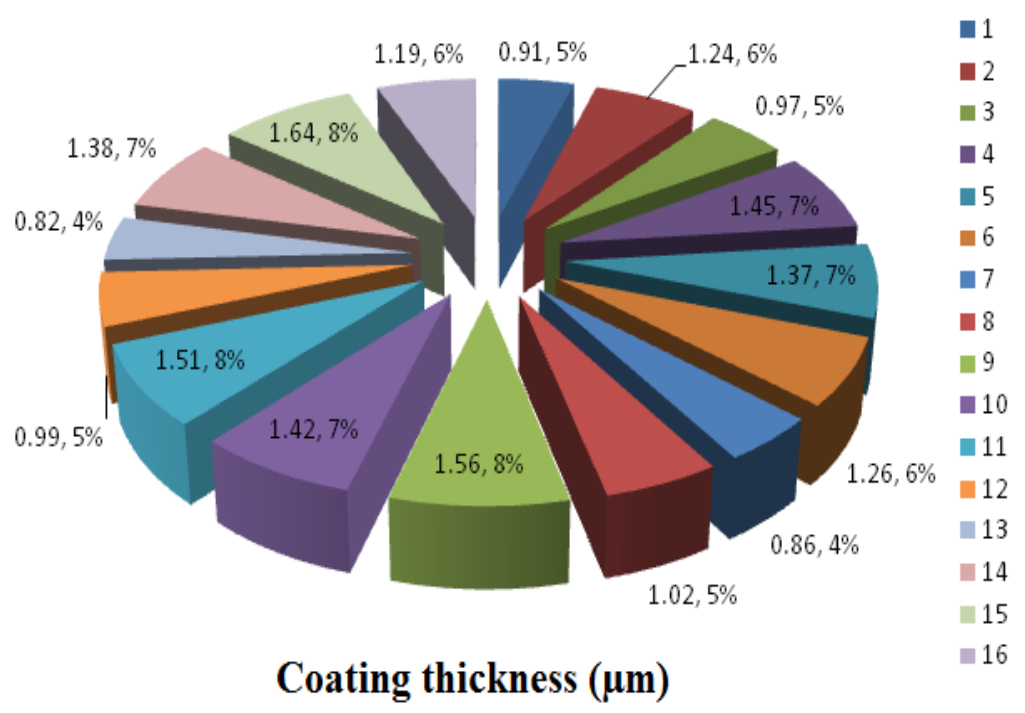

Figure 2. 3D Pie Chart for Coating Thickness in Electroplating

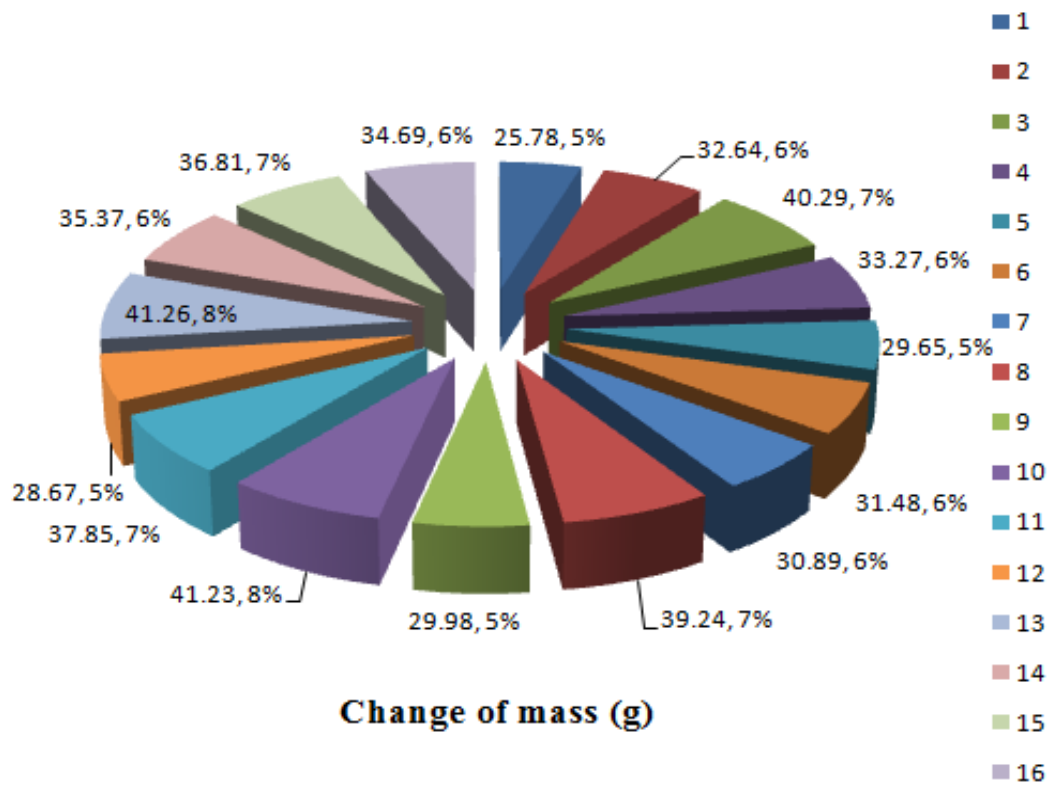

Figure 3. 3D Pie Chart for Change of Mass in Electroplating

Figure 2 clearly shows that the 3D Pie chart for coating thickness in electroplating, more than $1.5 \mu \mathrm{m}$ of coating thickness reflected in terms of $8 \%$. The experimental trail number fifteenth proved the maximum of coating thickness such as $1.64 \mathrm{~mm}$ was obtained. Figure 3 illustrated that the 3D Pie chart for change of mass in electroplating, in this analysis more than $41 \mathrm{~g}$ of change of mass are reflected in $8 \%$. Maximum change of mass was obtained as $41.26 \mathrm{~g}$ by thirteenth experimental trial. 


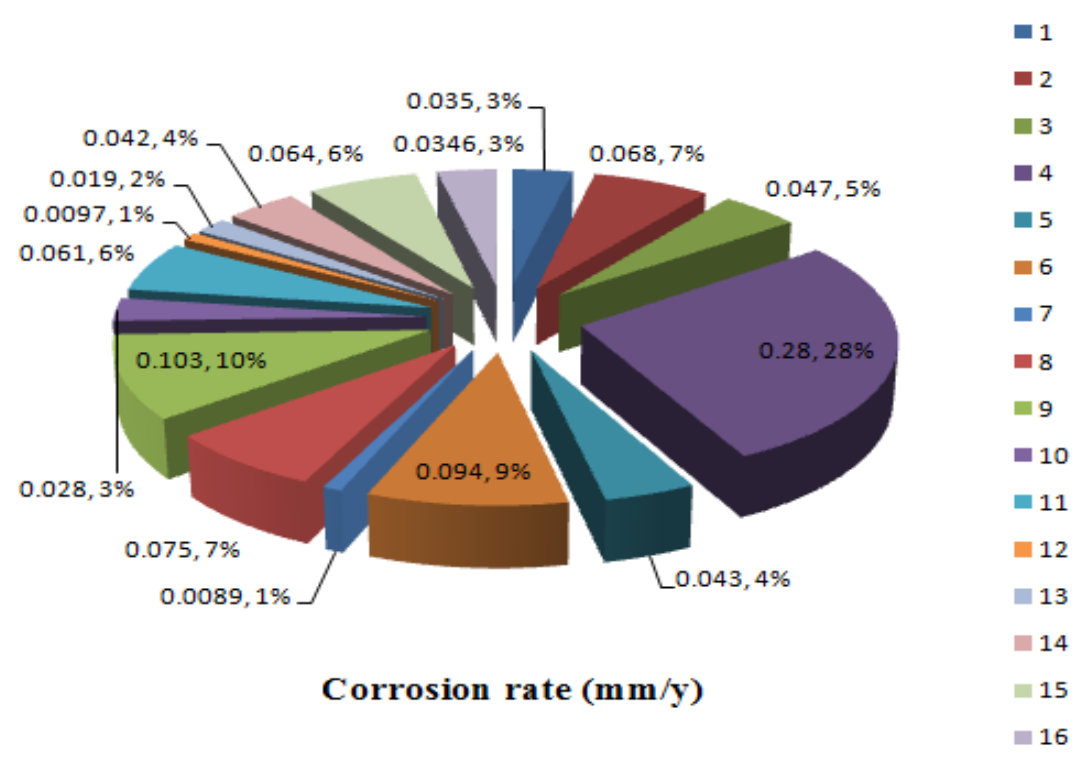

Figure 4. 3D Pie Chart for Corrosion Rate in Electroplating

In Figure 4. presented the 3D Pie chart for corrosion rate in electroplating, for this study less than $0.008 \mathrm{~mm} / \mathrm{yr}$ of corrosion rate was reflected in terms of $1 \%$. Minimum corrosion rate was recorded as $0.0097 \mathrm{~mm} / \mathrm{yr}$ by $12^{\text {th }}$ experimental trial.

Table 5 Comparison of Experimented and Predicted Values of Electroplating Process

\begin{tabular}{|c|c|c|c|c|c|c|}
\hline \multirow{2}{*}{$\begin{array}{c}\text { Trial } \\
\text { No. }\end{array}$} & \multicolumn{2}{|c|}{ Coating Thickness $(\boldsymbol{\mu m})$} & \multicolumn{2}{c|}{ Change of Mass (g) } & \multicolumn{2}{c|}{ Corrosion Rate (mm/y) } \\
\cline { 2 - 7 } & Experimented & Predicted & Experimented & Predicted & Experimented & Predicted \\
\hline $\mathbf{1}$ & 0.81 & 0.89 & 23.78 & 24.33 & 0.0350 & 0.0477 \\
\hline $\mathbf{2}$ & 1.24 & 1.25 & 32.64 & 34.91 & 0.0680 & 0.0776 \\
\hline $\mathbf{3}$ & 0.97 & 1.18 & 39.29 & 39.18 & 0.0470 & 0.0678 \\
\hline $\mathbf{4}$ & 1.19 & 1.25 & 33.27 & 33.55 & 0.2200 & 0.2367 \\
\hline $\mathbf{5}$ & 1.05 & 1.17 & 29.65 & 29.93 & 0.0001 & 0.0002 \\
\hline $\mathbf{6}$ & 1.26 & 1.47 & 30.02 & 30.37 & 0.0940 & 0.1148 \\
\hline $\mathbf{7}$ & 0.86 & 0.87 & 30.89 & 33.16 & 0.0089 & 0.0185 \\
\hline $\mathbf{8}$ & 0.89 & 1.00 & 36.24 & 37.79 & 0.0750 & 0.0877 \\
\hline $\mathbf{9}$ & 1.56 & 1.57 & 29.98 & 32.25 & 0.1030 & 0.1126 \\
\hline $\mathbf{1 0}$ & 1.32 & 1.40 & 38.23 & 39.78 & 0.0280 & 0.0407 \\
\hline $\mathbf{1 1}$ & 1.28 & 1.31 & 37.85 & 38.13 & 0.0010 & 0.0177 \\
\hline $\mathbf{1 2}$ & 0.99 & 1.20 & 26.67 & 27.56 & 0.0097 & 0.0305 \\
\hline $\mathbf{1 3}$ & 0.82 & 1.03 & 39.89 & 40.15 & 0.0190 & 0.0398 \\
\hline $\mathbf{1 4}$ & 1.13 & 1.18 & 35.37 & 35.65 & 0.0008 & 0.0012 \\
\hline $\mathbf{1 5}$ & 1.57 & 1.62 & 34.81 & 35.36 & 0.0640 & 0.0767 \\
\hline $\mathbf{1 6}$ & 1.19 & 1.20 & 34.69 & 36.96 & 0.0346 & 0.0442 \\
\hline
\end{tabular}


In the Table 5 tabulated the comparison of experimented and predicted values of electroplating process effectively. Three output response values of Coating thickness $(\mu \mathrm{m})$, Change of mass $(\mathrm{g})$ and Corrosion rate $(\mathrm{mm} / \mathrm{y})$ recorded through experimental work as well as the predicted values are analyzed through DOE mode. From these comparisons all the experimental values are within the limits of predicted values.

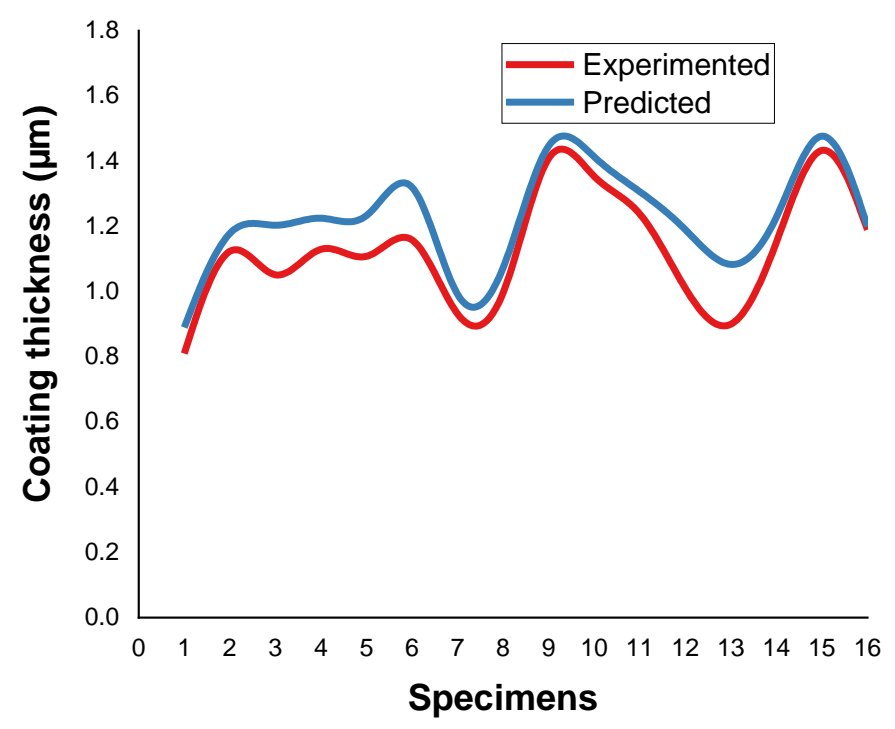

Figure 5. Number of Specimens and Coating Thickness Graph

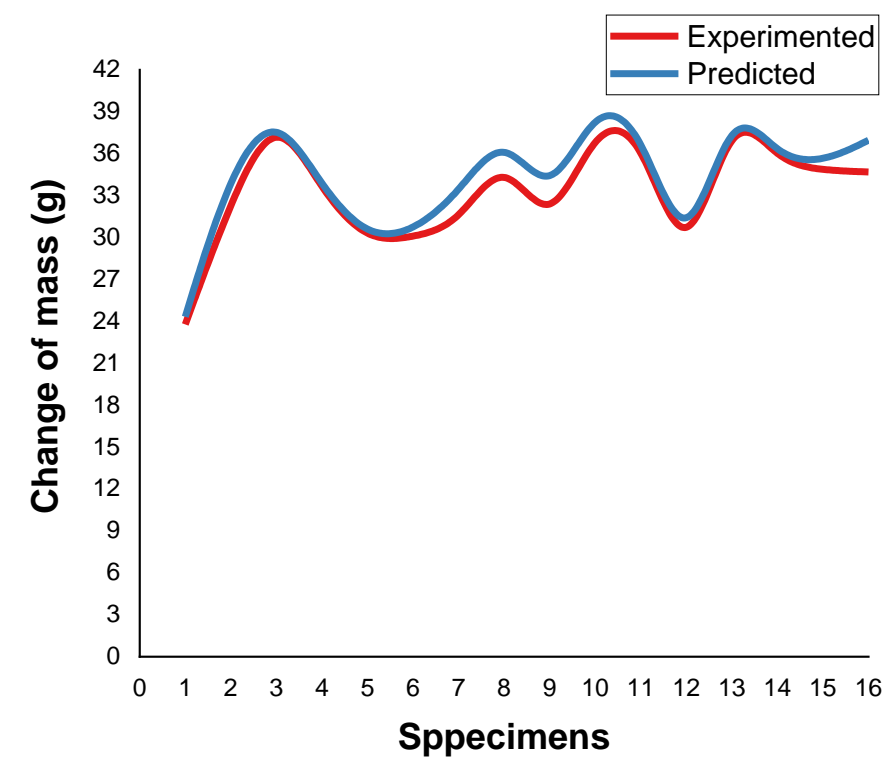

Figure 6. Number of Specimens and Change of Mass Graph 


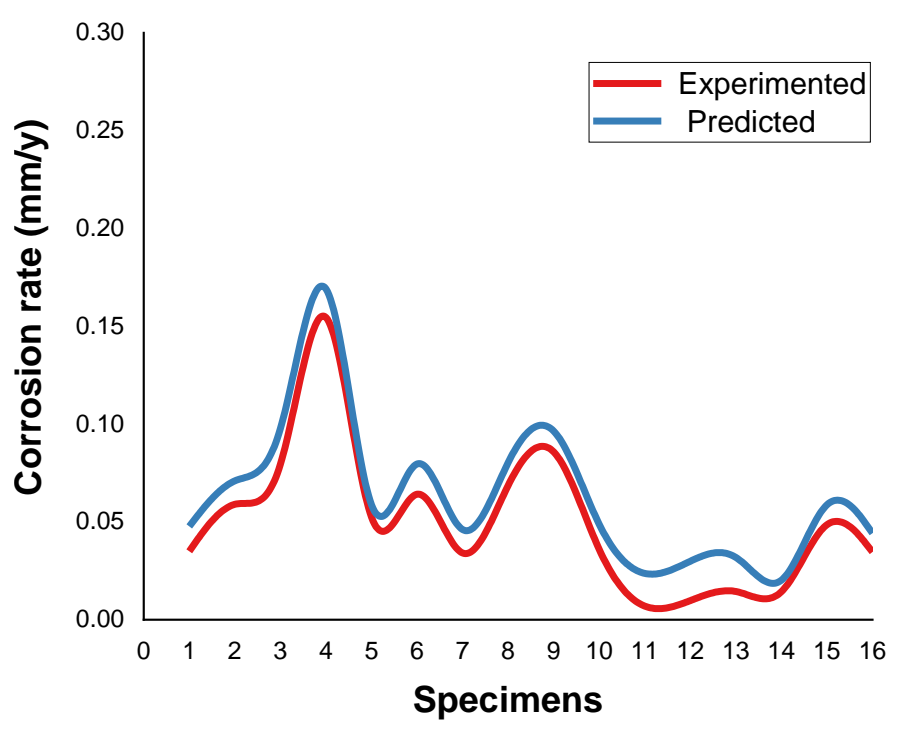

Figure 7. Number of Specimens and Corrosion Rate Graph

In the Figure 5 illustrates that the number of specimens and coating thickness, Figure 6 illustrates number of specimens and change of mass and Figure 7presented the number of specimens and corrosion rate. All three graphs evidently registered that the experimental values were within the limit of predicted values.

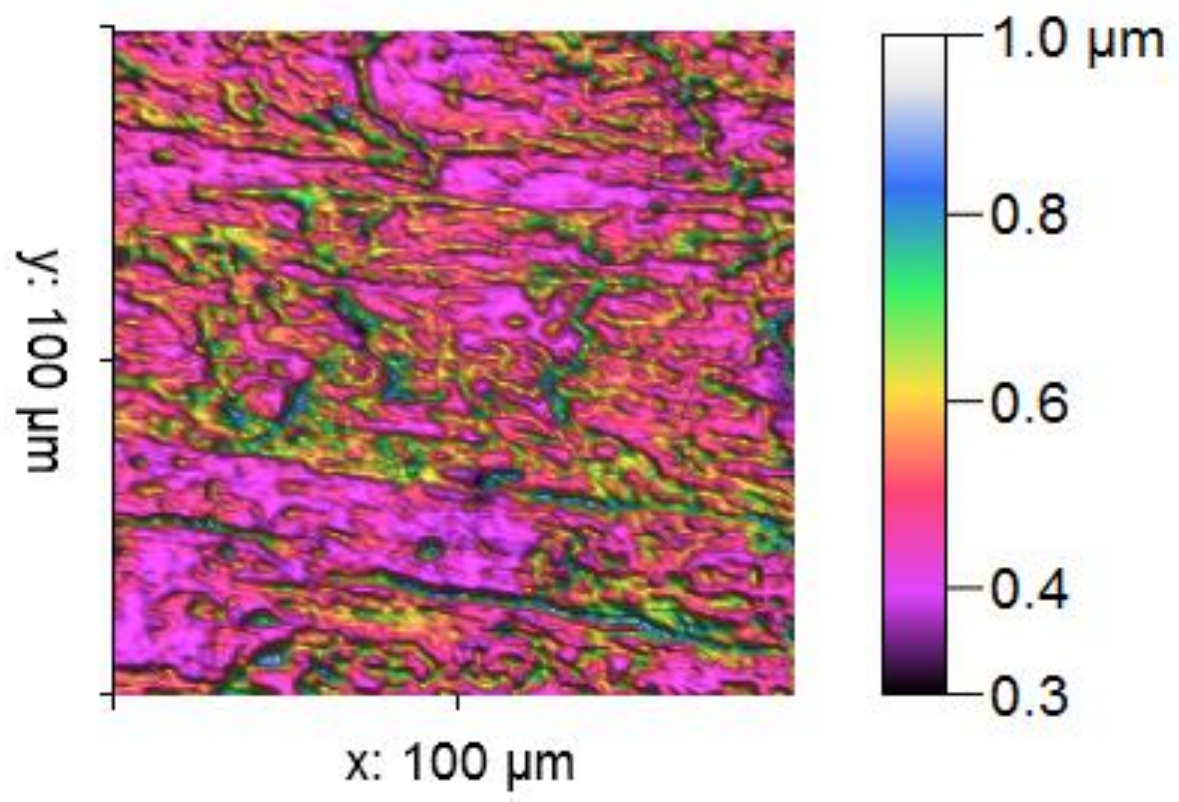

Figure 8. 2D Profilometry Images of Corrosion Rate of the Material 

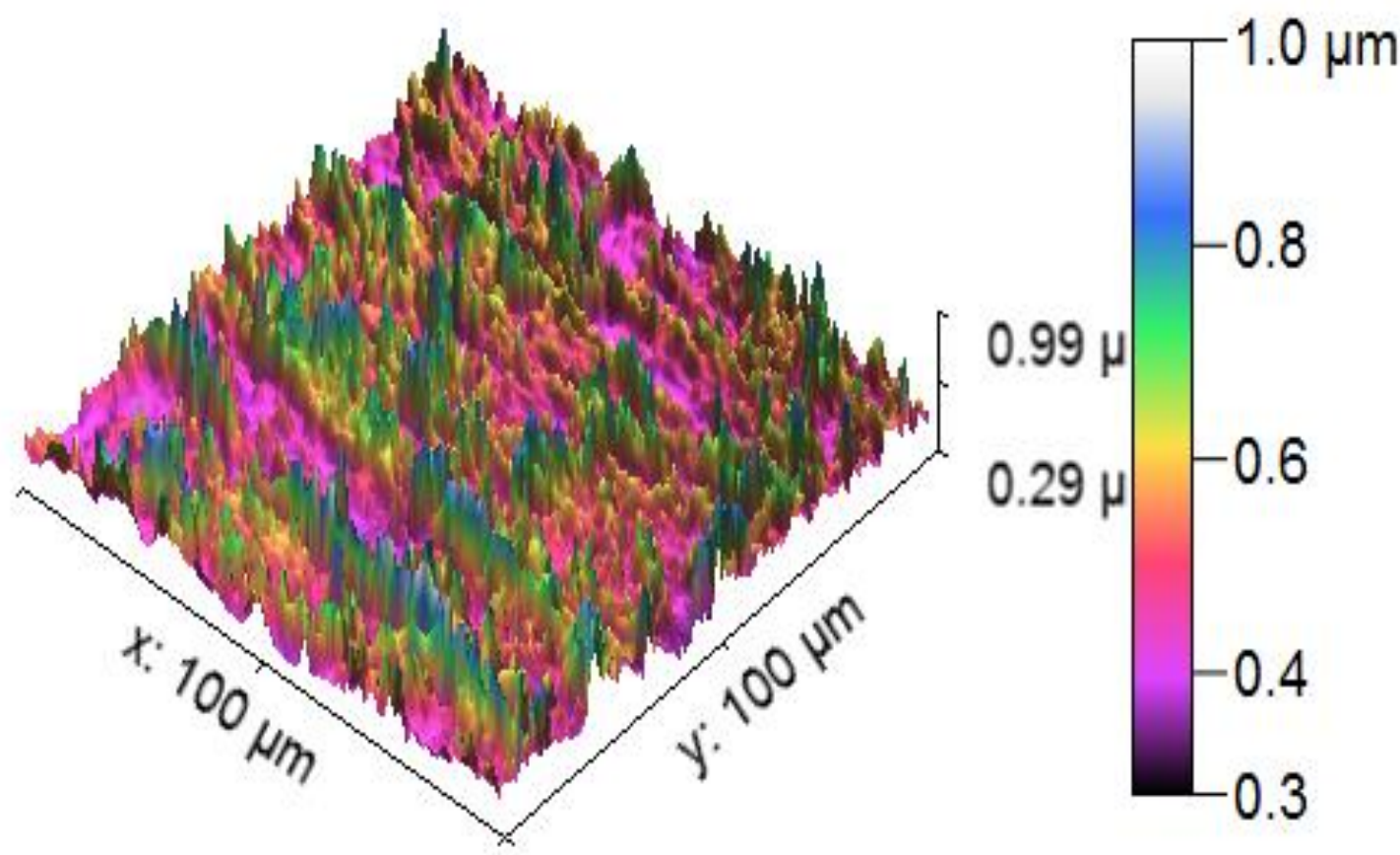

Figure 8. 3D Profilometry Images of Corrosion Rate of the Material

The Figure $8 \& 9$ visibly shows that the 2D and 3D profilometry images of corrosion rate of the material. The pink colour revealed that the maximum corrosion rate obtained of the material, the bluish colour denoted that the minimum corrosion rate.

\section{Conclusion}

The electroplating of mild steel coupling was successfully conducted and the output values of Coating thickness $(\mu \mathrm{m})$, Change of mass $(\mathrm{g})$ and Corrosion rate $(\mathrm{mm} / \mathrm{y})$ were checked with predicted value. The result of this work was demonstrated as follows:

- From the electroplating analysis the maximum coating thickness $1.64 \mathrm{~mm}$ was found by applying of $0.9 \mathrm{amps} / \mathrm{dm}^{2}$ of current density, $14 \mathrm{~g} / \mathrm{L}$ of concentration of Zinc, 60 min of coating time and $50{ }^{\circ} \mathrm{C}$ of temperature. Further the maximum change of mass $41.26 \mathrm{~g}$ was evaluated by the influence of $0.9 \mathrm{amps} / \mathrm{dm}^{2}$ of current density, $10 \mathrm{~g} / \mathrm{L}$ concentration of Zinc, 90 min of coating time and $30{ }^{\circ} \mathrm{C}$ temperatures.

- Minimum corrosion rate was found to be as $0.0097 \mathrm{~mm} / \mathrm{yr}$ and the parameters influenced were $0.7 \mathrm{amps} / \mathrm{dm}^{2}$ of current density, $16 \mathrm{~g} / \mathrm{L}$ of concentration of Zinc, 60 min of coating time and $20{ }^{\circ} \mathrm{C}$ of temperature.

- Among sixteen experimental trails, the fifteenth number proved the maximum of coating thickness such as $1.64 \mathrm{~mm}$ was obtained. Maximum change of mass was recorded as $41.26 \mathrm{~g}$ by thirteenth experimental trial. For corrosion study minimum corrosion rate was recorded as $0.0097 \mathrm{~mm} / \mathrm{yr}$ by twelth experimental trial.

- All three output response values of Coating thickness $(\mu \mathrm{m})$, Change of mass $(\mathrm{g})$ and Corrosion rate $(\mathrm{mm} / \mathrm{y})$ were recorded by experimental work as well as the DOE mode. From these comparisons all the experimental values were within the limits of predicted values. 


\section{Acknowledgements}

The authors thank the Management of Department of Mechanical Engineering, Institute of Technology - Hawassa University, Ethiopia and Department of Mechanical Engineering, Bharath Institute of Higher Education and Research, Chennai, India for the encouragement.

\section{References}

1. Poroch-Seritan, M, Bulai, P, Severin, T.L and Gutt, G, 'Modeling and optimization study on hardness of Ni-Fe alloythin films through electroplating process', Applied Mechanics and Materials, 657, (2014), pp. 286-290.

2. $\quad$ Sathish $T$ and Karthick $S$, 'Wear behaviour analysis on Aluminium Alloy 7050 with Reinforced SiC through Taguchi approach', Journal of Materials Research and Technology, Elsevier Publisher, Vol. 9, no. 3,(2020), pp. 3481-3487.

3. Radwan, A.B. Mohamed, A.M.A. Abdullah, A.M and Al-Maadeed, M.A, 'Corrosion Protection of Electrospun PVDF-ZnO Superhydrophobic Coating, Surface and Coating Technology, Vol. 289, (2016), pp. 136-143.

4. Sathish T, 'Experimental Study and Model Development for ON - LINE Drill Wear Monitoring System using Lab View', International Journal of Recent Technology and Engineering, Blue Eyes Intelligence Engineering \& Sciences Publication, Vol. 7, no. 6, (2019),pp. 281-286.

5. Zhao, Y, Zhang, Z; Yu, L and Jiang, T, 'Hydrophobic polystyrenelelectro-Spun Polyaniline Coatings for Corrosion Protection', Synthetic. Metals, Vol. 234, (2017), pp. 166-174.

6. Zhao, Y, Xing, C. Zhang, Z and Yu, L, 'Superhydrophobic polyanilinelpolystyrene micro/nanostructures as Anticorrosion Coatings', Reactive and Functional. Polymers, Vol. 119, (2017), pp. 95-104.

7. V.Mohanavel, K.S.Ashraffali, S.Prasath, T.Sathish, M.Ravichandran, Microstructural and tribological characteristics of $\mathrm{AA}^{2} 6351 / \mathrm{Si}_{3} \mathrm{~N}_{4}$ composites manufactured by stir casting, J Mater Res Technol 9 2020; 9: 14662-14672.

8. V.Mohanavel, K.Rajan, M.Ravichandran, 2016 Synthesis, characterization and properties of stir cast AA6351-aluminium nitride (AlN) composites, Journal of Materials Research, Vol. 31, (2016),pp. 3824-3831.

9. Croccolo D, De Agostinis M, Fini S and Olmi G, 'Tribological properties of bolts depending on different screw coatings and lubrications', An experimental study. Tribology International, Vol. 107, (2017), pp. 199-205.

10. Sathish T, 'Investigation on Microstructural and Mechanical Properties of $\mathrm{Cu}$ reinforced with Sic composites Prepared by Microwave sintering Process', Journal of New Materials for Electrochemical Systems, Vol. 22, no. 1, (2019),pp. 5-9.

11. Loukil $N$ and Feki $M$, 'Electro-deposition of $\mathrm{Zn}-\mathrm{Mn}$ alloy coatings deposited from acidic chloride baths, Effect of deposition conditions on the Zn-Mn electroplating, morphological and structural characterization', Applied Surface Science, Vol. 410, (2017), pp. 574-584.

12. Sathish T, 'Experimental Investigation of Machined Hole and optimization of Machining parameters using Electrochemical Machining', Journal of Materials Research and Technology, Vol. 8, no. 5, (2019), pp. 4354-4363. 